\title{
Epididymal function in the boar in relation to the fertilizing ability of spermatozoa
}

\author{
R. H. F. Hunter, W. Holtz† and P. J. Henfrey \\ Department of Agricultural Zoology, ${ }^{*}$ School of Agriculture, University of Edinburgh, U.K. and \\ $\dagger$ Department of Animal Science, University of Göttingen, West Germany
}

The role of the epididymis in relation to the development of fertilizing ability in populations of spermatozoa has been examined in several mammals since the classical experiments of Young (1929, 1931 ) in the guinea-pig, and in recent years this region of the reproductive tract has been the subject of intensive study (see reviews by Orgebin-Crist, 1969; Glover \& Nicander, 1971; Glover, 1974). Although a number of androgen-dependent phenomena in the epididymal duct have been characterized and a series of morphological and physiological changes in the sperm cells themselves have been noted, the precise modifications that confer fertilizing ability on individual spermatozoa still remain to be clarified. For domestic animals, it is important to analyse variation in the functional ability of spermatozoa taken from different regions of the epididymal duct and to relate these to the extent of epididymal depletion that occurs during exhaustive mating or artificial collection of semen samples. This can be achieved in a limited manner by using the position of the cytoplasmic droplet as a marker (Henfrey, 1974). The following study represents a preliminary examination of the development of fertilizing ability of spermatozoa from the epididymis of the boar, for which there is only limited information (Holtz \& Smidt, 1976); the timing of sperm capacitation is also presented in relation to the function of the epididymal duct.

\section{Methods}

Intact epididymides were obtained at castration from 4 German Landrace boars and post mortem from 12 Large White boars; all animals were sexually mature. Immediately after castration or slaughter, the testes and adjoining reproductive tracts were placed in a vacuum flask $\left(30-32^{\circ} \mathrm{C}\right)$ and brought to the laboratory within $45 \mathrm{~min}$. Sperm suspensions were prepared from one of six regions of the epididymal duct, and compared for fertilizing ability in the same test female with a control sample of spermatozoa prepared from the distal cauda epididymidis or ductus deferens of the same boar by aspiration through a 26 -gauge needle into a $1 \mathrm{ml}$ plastic syringe containing $0.05 \mathrm{ml}$ Eagle's medium or medium TC 199 at $34^{\circ} \mathrm{C}$. To obtain spermatozoa from the corpus epididymidis, small incisions were made in the duct and the contents released using light digital pressure and again aspirated into a syringe. Suspensions were mixed by gentle movements of the syringe plunger, after which sperm motility was estimated using phase-contrast optics and scored on a subjective scale of 1 to 5. Material prepared in this manner was inseminated within $90 \mathrm{~min}$ of castration or slaughter of the boar.

The fertilizing ability of the various sperm suspensions was tested by surgical insemination into the oviducts of Large White or Landrace gilts weighing 110-140 kg. Oestrous cycles were checked using a mature boar, and ovulation induced with a single i.m. injection of 500 i.u. HCG (Chorulon: Organon) given during pro-oestrus. Ovulation was assumed to occur 41-42 hr after HCG injection (Hunter, 1967), this timing being verified during surgery. The reproductive tract was exposed by mid-ventral laparotomy under general anaesthesia, and insemination performed using separate syringes and 20-gauge needles for each sperm suspension. Approximately $0.05 \mathrm{ml}$ of the experimental sample containing a total of $0.2-0.5 \times 10^{6}$ spermatozoa was introduced through the utero-tubal

\footnotetext{
- Postal address: West Mains Road, Edinburgh, EH9 3JG, U.K.
} 
junction into the lower $1.0 \mathrm{~cm}$ of the isthmus shortly before or after the time of ovulation ( $40-44 \mathrm{hr}$ after HCG injection). The contralateral oviduct receiving the control sperm sample was treated similarly and identified by a silk thread in the mesometrium. The reproductive tract was replaced immediately after these procedures and the incision closed.

In order to examine the time required for capacitation in various populations of epididymal spermatozoa, 6 gilts were subjected to a second laparotomy between $4 \mathrm{hr} 0 \mathrm{~min}$ and $4 \mathrm{hr} 26 \mathrm{~min}$ after insemination (Table 1). At this time, the contents of each oviduct were flushed from the ovarian end with medium TC 199 into glass dishes. The recovered eggs were prepared as described below, and examined for evidence of sperm penetration and resumption of the second meiotic division. To examine the influence of the insemination treatments on the overall proportion of fertilization and early embryonic development, 20 animals were slaughtered between 1 and 6 days after surgery. The reproductive tract was flushed at autopsy with Tyrode's solution, and whole-mount preparations made of eggs and embryos. After fixing in $25 \%$ acetic alcohol and staining with $0.5 \%$ orcein in $45 \%$ acetic acid, they were examined by phase-contrast microscopy.

Table 1. Examination of the time required for capacitation of different populations of epididymal spermatozoa based on the number of activated eggs* recovered from the oviducts of 6 gilts at various intervals after surgical insemination

\begin{tabular}{|c|c|c|c|c|c|c|c|}
\hline \multirow{3}{*}{$\begin{array}{c}\text { Gilt } \\
\text { number }\end{array}$} & \multirow{3}{*}{$\begin{array}{l}\text { Interval between } \\
\text { insemination and } \\
\text { egg recovery }\end{array}$} & \multirow{2}{*}{\multicolumn{2}{|c|}{$\frac{\text { Upper corpus epididymidis }}{\text { No. of eggs }}$}} & \multirow{2}{*}{\multicolumn{2}{|c|}{$\frac{\text { Lower corpus epididymidis }}{\text { No. of eggs }}$}} & \multirow{2}{*}{\multicolumn{2}{|c|}{$\frac{\text { Distal cauda epididymidis }}{\text { No. of eggs }}$}} \\
\hline & & & & & & & \\
\hline & & Recovered & Penetrated* & Recovered & Penetrated* & Recovered & Penetrated* \\
\hline $1 \mathrm{~A}$ & $4 \mathrm{hr}$ & 5 & $\mathbf{0}$ & & - & 4 & 0 \\
\hline $2 A$ & $4 \mathrm{hr}$ & 8 & $\mathbf{0}$ & & & 5 & $\mathbf{0}$ \\
\hline $3 \mathrm{~A}$ & $4 \mathrm{hr} 4 \mathrm{~min}$ & 7 & 4 & & & 12 & $\mathbf{0}$ \\
\hline $4 \mathrm{~A}$ & $4 \mathrm{hr} 6 \mathrm{~min}$ & & & 6 & 5 & 1 & 0 \\
\hline $5 \mathrm{~A}$ & $4 \mathrm{hr} 16 \mathrm{~min}$ & 11 & 10 & & & 5 & $\mathbf{0}$ \\
\hline \multirow[t]{2}{*}{$6 \mathrm{~A}$} & $4 \mathrm{hr} 26 \mathrm{~min}$ & 6 & 6 & & & 2 & 0 \\
\hline & Total & 37 & $20\left(54.1^{\circ}\right.$ & 6 & $5\left(83.3^{\circ}\right.$ & 29 & 0 \\
\hline
\end{tabular}

* Eggs classified as penetrated or activated contained a spermatozoon in the vitellus and showed anaphase or telophase of the second meiotic division or the very early pronuclear stage.

All suspensions of spermatozoa showed reasonable progressive motility at the time of insemination ( $>2$ out of 5 ), although none scored higher than $3 \frac{1}{2}-4$ on the scale employed. This estimate of motility was characteristic of the suspensions prepared from the various regions of the epididymis, but was also found in spermatozoa from the ductus deferens.

\section{Capacitation}

The results in Table 1 indicate that a suspension of spermatozoa prepared from the upper corpus epididymidis contained sufficient fertile cells to penetrate and activate a proportion of the eggs recovered from $3 / 5$ oviducts. All the eggs recovered $4 \mathrm{hr} 26 \mathrm{~min}$ after insemination in one test were activated, and 10/11 were activated $4 \mathrm{hr} 16 \mathrm{~min}$ after insemination in another trial. By contrast, none of the eggs recovered from the contralateral oviducts at similar intervals after instillation of sperm suspensions prepared from the cauda epididymidis of the same boars was fertilized, although spermatozoa $(1->60)$ were associated with the eggs in 4 of the 6 animals. The chromosomes were arranged at second meiotic metaphase in all 29 eggs.

The most advanced stage of fertilization observed in the eggs activated by spermatozoa taken from the upper corpus epididymidis was second meiotic telophase or the very early pronuclear stage; both configurations indicate recent penetration of the vitellus. In association with the zona pellucida of these eggs, sperm numbers ranged from 1 to 53 , with a mean of $12 \cdot 1$. In the 2 animals in which 
spermatozoa from the upper corpus had not activated eggs within 4 hr $0 \mathrm{~min}$ of insemination, only a single spermatozoon was seen attached to 1 of 13 eggs.

Eggs were recovered from one animal $4 \mathrm{hr} 06 \mathrm{~min}$ after insemination of a suspension of spermatozoa prepared from the lower corpus epididymidis. Five of a total of 6 eggs were activated in this trial, with a mean sperm number/egg of 53 (range 32->90). The single egg recovered after insemination of spermatozoa from the cauda epididymidis into the contralateral tube was not activated, although there were many spermatozoa $(55-60)$ on the surface of the zona pellucida.

\section{Fertilizing ability}

In the 20 gilts examined at autopsy (Table 2), the mean proportion of eggs or embryos recovered was $76.8 \%$. Spermatozoa taken from the ductus deferens gave an overall incidence of fertilization of $91 \%$. Suspensions of spermatozoa prepared from the upper corpus epididymidis fertilized eggs in only one instance in this series, but spermatozoa gradually attained this ability in the mid-and lower corpus regions, becoming fully functional by the time they reached the proximal cauda epididymidis (Table 2).

Table 2. The numbers of eggs recovered and fertilized when examined at autopsy between Days 1 and 6 after surgical insemination of 20 gilts with a suspension of spermatozoa prepared from the epididymis into one oviduct

(A), and a control sample prepared from the ductus deferens of the same boar into the other oviduct (B)

\begin{tabular}{|c|c|c|c|c|c|c|}
\hline \multirow[b]{2}{*}{$\begin{array}{c}\text { Origin of } \\
\text { spermatozoa }\end{array}$} & \multicolumn{2}{|c|}{ No. of females } & \multicolumn{2}{|c|}{ Eggs from oviduct $A$} & \multicolumn{2}{|c|}{ Eggs from oviduct B } \\
\hline & Inseminated & $\begin{array}{l}\text { Yielding } \\
\text { fertilized } \\
\text { eggs }\end{array}$ & Recovered & $\begin{array}{c}\text { Fertilized } \\
\text { and developing } \\
\text { normally }(\%)\end{array}$ & Recovered & $\begin{array}{c}\text { Fertilized } \\
\text { and developing } \\
\text { normally }(\%)\end{array}$ \\
\hline \multicolumn{7}{|c|}{ Corpus epididymidis } \\
\hline Upper & 5 & 1 & 29 & $3(10 \cdot 4)$ & 27 & $24(88.9)$ \\
\hline Mid- & 5 & 3 & 23 & $7(30 \cdot 4)$ & 31 & $28(90 \cdot 3)$ \\
\hline Lower & 4 & 3 & 17 & $9(52 \cdot 9)$ & 18 & $16(88 \cdot 9)$ \\
\hline \multicolumn{7}{|c|}{ Cauda epididymidis } \\
\hline Proximal & 2 & 2 & 13 & $12(92 \cdot 3)$ & 10 & $10(100)$ \\
\hline Mid- & 2 & 2 & 11 & $9(81 \cdot 8)$ & 11 & $11(100)$ \\
\hline Distal & 2 & 2 & 11 & $11(100)$ & 14 & $12(85 \cdot 7)$ \\
\hline Total & 20 & 13 & 104 & 51 & 111 & $101(90 \cdot 9)$ \\
\hline
\end{tabular}

\section{Discussion}

Although limited in extent, these results are in general agreement with the report of Holtz \& Smidt (1976), and indicate that boar spermatozoa gradually acquire fertilizing ability as they proceed through the corpus region of the epididymal duct. These findings on the 'fertility profile' (Horan \& Bedford, 1972) in the epididymis of the boar differ therefore from the results of similar studies in the rabbit, in which very few fertile spermatozoa are present in the middle region of the corpus epididymidis, significant numbers first appearing only in the lower portion of the corpus (Bedford, 1966; Orgebin-Crist, 1967), and in the Syrian hamster, in which spermatozoa do not normally acquire the ability to penetrate eggs until they reach the proximal portion of the cauda epididymidis (Horan \& Bedford, 1972).

The finding that boar spermatozoa from the upper corpus epididymidis activated eggs in 3 animals within $4 \mathrm{hr} 26 \mathrm{~min}$ of insemination whereas spermatozoa prepared from the distal cauda were unable to do so in the same time, even though they were associated with the eggs, was of particular interest. These results may suggest that during transit along the epididymal duct, the sperm cells become invested with some form of inhibitor involved in stabilization of the plasma membrane and 
complement of acrosomal enzymes (see Bedford, 1970). Spermatozoa from the cauda epididymidis, having been exposed to the putative inhibitor, should therefore be retarded in their expression of capacitation when compared with competent spermatozoa liberated higher in the epididymal duct. Specific observations in conflict with this reasoning, however, are twofold. First, a sperm suspension prepared from the lower corpus region also displayed a temporal advantage in terms of fertilizing ability over spermatozoa from the cauda epididymidis, thereby inferring that any addition of inhibiting substance must also be occurring in the portion of the epididymal duct between the lower corpus and the cauda. Second, the work of Suominen \& Setchell (1972) on mature boars indicated secretion of enzyme inhibitor into rete testis fluid, as well as into the epididymal duct. Further biochemical and physiological studies are therefore needed to reconcile these various findings.

Hunter \& Hall (1974) observed that the uterus and oviducts of oestrous gilts acted synergistically to promote capacitation of ejaculated boar spermatozoa within $4 \mathrm{hr}$ of surgical insemination into the uterus, whereas approximately $6 \mathrm{hr}$ was needed for capacitation after insemination of ejaculated spermatozoa directly into the oviducts. In the present study, however, spermatozoa from the upper corpus epididymidis were able to activate a proportion of the eggs within $4 \mathrm{hr}$ of insemination directly into the oviducts. Leaving aside minor differences in material and technique between the two studies, these findings again suggest that spermatozoa from the upper corpus possess some advantage in terms of the time required for capacitation over spermatozoa prepared from the cauda epididymidis (present study) or from the ejaculate (Hunter \& Hall, 1974). A reasonable interpretation of the difference in timing between the populations of spermatozoa examined would be that capacitation of ejaculated boar spermatozoa or those liberated from the distal cauda is delayed because of some factor in epididymal or whole seminal plasma which is not associated with spermatozoa in the upper corpus epididymidis, or is only present there in a low concentration.

The investigation received financial support from the Agricultural Research Council. We also wish to thank Mr R. Nichol, Mrs J. Ebeling and Mr H. Wendhausen for technical assistance, Mr A. Gardiner for supervision of the animals, and Professors F. W. H. Elsley and D. Smidt for their interest in this work.

\section{References}

BEDFORD, J.M. (1966) Development of the fertilizing ability of spermatozoa in the epididymis of the rabbit. J. exp. Zool. 163, 319-330.

BEDFORD, J.M. (1970) Sperm capacitation and fertilization in mammals. Biol. Reprod. 2, Suppl. 2, 128-158.

GLOVER, T.D. (1974) Recent progress in the study of male reproductive physiology. In Reproductive Physiology, MTP International Review of Science; Physiology, Series One, Vol. 8, Ch. 9, pp. 221-277. Ed. R. O. Greep. Butterworths, London.

Glover, T.D. \& NiCANDER, L. (1971) Some aspects of structure and function in the mammalian epididymis. J. Reprod. Fert., Suppl. 13, 39-50.

HENFREY, P.J. (1974) Some aspects of epididymal function in the boar. Honours thesis, Faculty of Science, University of Edinburgh.

Holtz, W. \& Smidt, D. (1976) The fertilizing capacity of epididymal spermatozoa in the pig. $J$. Reprod. Fert. 46, 227-229.

HoRAN, A.H. \& BEDFORD, J.M. (1972) Development of the fertilizing ability of spermatozoa in the epididymis of the Syrian hamster. J. Reprod. Fert. 30, 417-423.
Hunter, R.H.F. (1967) Porcine ovulation after injection of human chorionic gonadotrophin. Vet. Rec. 81, 21-23.

HunTeR, R.H.F. \& HalL, J.P. (1974) Capacitation of boar spermatozoa: synergism between uterine and tubal environments. J. exp. Zool. 188, 203-214.

ORGEBIN-CRIST, M.C. (1967) Sperm maturation in rabbit epididymis. Nature, Lond. 216, 816-818.

OrGEBIN-CrIST, M.C. (1969) Studies on the function of the epididymis. Biol. Reprod., Suppl. 1, 155-175.

SuOminen, J. \& Serchell, B.P. (1972) Enzymes and trypsin inhibitor in the rete testis fluid of rams and boars. J. Reprod. Fert. 30, 235-245.

YounG, W.C. (1929) A study of the function of the epididymis. I. Is the attainment of full spermatozoon maturity attributable to some specific action of the epididymal secretion? J. Morph. 47, 479-495.

YounG, W.C. (1931) A study of the function of the epididymis. III. Functional changes undergone by spermatozoa during their passage through the epididymis and vas deferens in the guinea pig. J. exp. Biol. 8, 151-162. 